・生物编目・

\title{
中国莎草科新组合与新名称
}

\author{
张树仁 ${ }^{*} \quad$ 毕海燕 2 \\ 1 (中国科学院植物研究所系统与进化植物学国家重点实验室, 北京 100093) \\ 2 (北京自然博物馆, 北京 100050)
}

\section{A new combination and a replacement name of Cyperaceae from China}

\author{
Shuren Zhang ${ }^{{ }^{*}}$, Haiyan $\mathrm{Bi}^{2}$
}

1 State Key Laboratory of Systematic and Evolutionary Botany, Institute of Botany, Chinese Academy of Sciences, Beijing 100093

2 Beijing Museum of Natural History, Beijing 100050

在编写《中国生物物种名录》第一卷第二分册 莎草科的过程中, 作者发现先前发表于莎草科水莎 草属(Juncellus (Griseb.) C. B. Clarke)中的一个变种

头状水莎草(Juncellus serotinus (Rottb.) C. B. Clarke var. capitatus D. Z. Ma) (马德滋和刘惠兰, 1988)属于莎草属(Cyperus)植物; 先前发表于蔍草 属(Scirpus L.) 中的一个杂种一一间蔍草(Scirpus xintermedius Tang \& F. T. Wang) (唐进和汪发缵, 1961), 违反“International Code of Nomenclature for Algae, Fungi, and Plants (Melbourne Code)" (McNeill et al, 2012)的规则H.3.3, 名称不合法(见规则53.1), 且该杂种属于水葱属(Schoenoplectus)植物, 需用新 名称替代(见规则6.11)。相关的命名变动报道如下:

\section{1 新组合}

\section{头状水莎草}

Cyperus serotinus Rottb. var. capitatus (D. Z. Ma) S. R. Zhang \& H. Y. Bi, comb. nov.

Basionym: Juncellus serotinus (Rottb.) C. B. Clarke var. capitatus D. Z. Ma, Fl. Ningxia 2: 522 (1988). Type: China, Ningxia, Yinchuan, Dongmenwai, Aug. 1963, D. Z. Ma s.n. (holotype, NXAC).

本变种仅分布于宁夏银川, 为我国特有, 生于 水沟或池沼边。
头状水莎草最初由马德滋和刘惠兰(1988)发表 在水莎草属中，根据 Dai 等 (2010) 和 Goetghebeur (1998), 该属应该归并到莎草属。因此, 本变种也应 该组合到莎草属中。

头状水莎草 (Cyperus serotinus Rottb. var. capitatus (D. Z. Ma) S. R. Zhang \& H. Y. Bi)与原变种水 莎草(Cyperus serotinus Rottb. var. serotinus)的区别 在于: 小穗卵球形或长卵球形，长3-5 mm, 宽约2 $\mathrm{mm}$ ，紧密排列于辐射枝的顶端，几乎呈头状。

\section{2 新名称}

\section{中间水葱(中间薦草)}

Schoenoplectus ×intermedius S. R. Zhang \& H. Y. Bi, nom. nov.

Replaced synonym: Scirpus $\times$ intermedius Tang \& F. T. Wang, Fl. Reipubl. Popularis Sin. 11: 34, 224 (1961), non Thuill. (1799). Type: China, Yunnan, Dongchuan, 2 Sept. 1932, H. T. Tsai 51973B (holotype, PE!).

Schoenoplectiella $\times$ intermedia Hayas., J. Jap. Bot. 87(3): 183 (2012), syn. nov.

该杂种产于云南省东川市, 生长在湖边等湿地 上, 海拔约 $2,300 \mathrm{~m}$ 。其外形酷似滇水苟( (S. schoofii (Beetle) Sojak), 但小坚果的性状与萤萄 (Schoenoplectus juncoides (Roxb.) Palla)极为近似。 
因此，唐进和汪发缵(1961)认为可能是滇水苟和萤 萄的杂交种。我们研究了该杂种的模式标本, 其形 态特征确如唐进和汪发缵(1961)的描述, 而且目前 对于该杂种尚无更深入的研究, 所以这里仍然将其 处理为杂种。

Scirpus $\times$ intermedius Tang \& F. T. Wang发表于 1961年(唐进和汪发缵, 1961), 为Scirpus intermedius Thuill. (1799)的晚出同名。日本学者Hayasaka (2012) 曾基于该杂种发表替代名称 Schoenoplectiella xintermedia Hayas., 但Schoenoplectiella属的范围及 其与水葱属的系统关系目前尚不十分清晰(Shiels et al, 2014), 暂时不宜承认该属。根据Dai等(2010), 该 杂种的亲本萤落和滇水苾均属水苟属。因此, 这里 将其转移至水葱属中, 发表新名称Schoenoplectus xintermedius S. R. Zhang \& H. Y. Bi来替代Scirpus xintermedius Tang \& F. T. Wang这一非法名称, 并 将 Hayasaka (2012) 发表的 Schoenoplectiella $\times$ intermedia Hayas. 处理为一个新异名。

致谢: 感谢中国科学院植物研究所朱相云研究员在 命名法方面给予的热忱帮助。

\section{参考文献}

Dai LK, Liang SY, Zhang SR, Tang YC, Koyama T, Tucker
GC, Simpson DA, Noltie HJ, Strong MT, Bruhl JJ, Wilson KL, Muasya AM (2010) Cyperaceae. In: Flora of China, Vol. 23 (eds Wu CY, Raven PH, Hong DY), pp. 164-461. Science Press, Beijing \& Missouri Botanical Garden Press, St. Louis.

Goetghebeur P (1998) Cypearaceae. In: Families and Genera of Vascular Plants, Vol. 4 (ed. Kubitzki K), pp. 141-190. Springer, Berlin.

Hayasaka E (2012) Delineation of Schoenoplectiella Lye (Cyperaceae), a genus newly segregated from Schoenoplectus (Rchb.) Palla. Journal of Japanese Botany, 87, 169-186.

Ma DZ, Liu HL (1988) Flora Ningxiaensis, Vol. 2. Ningxia People's Publishing House, Yinchuan. (in Chinese) [马德 滋, 刘惠兰 (1988) 宁夏植物志(第二卷). 宁夏人民出版 社, 银川.]

McNeill J, Barrie FR, Buck WR, Demoulin V, Greuter W, Hawksworth DL, Herendeen PS, Knapp S, Marhold K, Prado J, Prud'Homme van Reine WF, Smith GF, Wiersema JH, Turland NJ (2012) International Code of Nomenclature for algae, fungi, and plants (Melbourne Code) adopted by the Eighteenth International Botanical Congress Melbourne, Australia, July 2011. Regnum Vegetabile 154. Koeltz Scientific Books, Köenigstein.

Shiels DR, Hurlbut DL, Lichtenwald SK, Monfils AK (2014) Monophyly and phylogeny of Schoenoplectus and Schoenoplectiella (Cyperaceae): evidence from chloroplast and nuclear DNA sequences. Systematic Botany, 39, 132-144.

Tang T, Wang FT (1961) Flora Reipublicae Popularis Sinicae, Vol. 11. Science Press, Beijing. (in Chinese) [唐进, 汪发缵 (1961) 中国植物志(第十一卷). 科学出版社, 北京.]

(责任编委: 严岳鸿 责任编辑: 黄祥忠) 